\title{
Development of a Sustainable Optimization Model for the Rehabilitation of Transport Infrastructure
}

\author{
András Bakô ${ }^{1}$, László Gáspár ${ }^{2}$ \\ ${ }^{1}$ Óbuda University, Bécsi út 96/b, 1034 Budapest, Hungary, bako@uni-obuda.hu \\ ${ }^{2}$ Széchenyi University, Egyetem tér 1, 9023 Győr, Hungary, gaspart@sze.hu
}

\begin{abstract}
About twenty years ago, the research activities aiming at the development of the optimal maintenance and rehabilitation strategies (models) of roads and bridges started in several countries, including Hungary. In the first foreign models, the deterioration depending on time and other parameters was given by Markov transition probability matrices. Due to the inaccuracies and inconsistencies of earlier models, a continuous model upgrading could have been carried out by many researchers world-wide. Besides, basically new models appeared in the literature, which are able to describe the actual processes more reliably. The research work of the authors of the paper has concentrated on Pavement Management Systems (PMSs) and Bridge Management Systems (BMSs). Since a common financing of roads and bridges is typical, a combined model of road pavement and bridge managements was developed by the authors increasing considerably the efficient use of available funds.
\end{abstract}

Keywords: Pavement Management; Bridge Management; Markov deterioration model; maintenance-rehabilitation and operation cost distribution (allocation)

\section{Introduction}

It was more than two decades ago that a systematic management modelling of transport infrastructure started in Hungary with the collaboration of experts in various fields (transport engineers, mathematicians, economists, meteorologists, etc.). The original goal was to develop cost-efficient systems for development, rehabilitation, maintenance and operation activities in the area. These models can provide effective tools for infrastructure (mainly road) managers to minimize their expenditures if given preconditions are fulfilled. A part of activities was the adaptation of various systems available and used in foreign countries; however, several of these are models based on Hungarian data sets, usually data time series, but every case, the procedure followed was the creation of the first version of a system 
(model), and long-term monitoring of its operation, then, based on the experiences gained during the monitoring, a new, updated model version is developed.

This paper presents the development phases of such a model that concentrates not only on economic aspects but also environmental (sustainability) ones, as well. (The importance of the problem can be highlighted by the fact that the net value of Hungarian public highway network - some 7,000 billion HUF $=28$ billion EUR exceeds $38 \%$ of the Hungarian national wealth). First of all, some basic information on the Road Asset Management System is presented. The main steps of this development process done in Hungary are: single stage network level optimization model, multi-stage model, combined pavement/bridge model and model with climate-dependent parameters.

One of the main development achievements related to multi-periodical model was the total optimization. Since the models available optimize various elements of the model separately. Because of the large size of the model, optimization algorithm was applied. Usually it is not true that the sum of the results of partial optimizations is equal to total optimum. (E.g. all separate elements are optimized in a single model). For this purpose, the optimization model developed in Hungary is more appropriate than the packages developed and traded by various professional software houses. Another significant novelty is the development of combined pavement and bridge management systems. The main advantage of the use of this system comes from the fact that usually the same fund (budget) is used for the management (construction, maintenance, rehabilitation, operation) of both infrastructure elements. The third important innovation is connected with the consideration of the effects of climate change in the long-range model development. The fourth significant research outcome is the inclusion of a parameter related to the change in traffic characteristics in the pavement deterioration model. Then a new algorithm based on the results coming from PMS/BMS model had been developed. This algorithm distributes optimally the available road-bridge funds among the regions (counties). Finally another algorithm has been created for funds distribution in the case of insufficiency of available financial means.

\section{Asset Management System}

The development, the maintenance and the operation of the high-valued road network can be considered as an extremely important task of the whole country needing a lot of money, human resources, machinery, materials, etc. Several subsystems were developed and being used all over the world to solve the problem mentioned and to allocate economically the necessary resources. However, this task is rather complex and the sum of the best solutions of various subsystems are not identical with the optimum of the operation of the whole system. That is why intensive research activities started in the topic some 20 years ago. It is called 
Asset Management System for Road Sector or Road Asset Management System. One of the most significant relevant basic research institutions is US Department of Transport Federal Highway Administration, Office of Asset Management (Asset [2]). Another important effort in this field has been done by an OECD Committee (Asset [3]). There are many definitions for this kind of asset management but each of them refers to a management system, a DSS (Decision Supporting System) and the cost efficiency on road construction, maintenance and operation, besides the model system has both long-term, strategic and short-term, actual elements (What [28]). This case, the term "asset" includes not only its actual gross or net value but also the funds needed for its maintenance throughout service life. The potential users of asset management include decision makers, road users, road proprietors, operators, etc. The Road Asset Management System has several components (Hudson et al. [25]):

- Road pavements

- Pavement structures and connected elements

- Bridges

- Tunnels

- Culverts

- Traffic engineering facilities (traffic signs, road paintings, road lighting)

- Traffic census facilities

- Information and monitoring systems

- Road construction, maintenance and operation machinery

- Road vehicles

- Parking and rest areas

- Roadside building connected with road rehabilitation, maintenance and operation

- Materials used and equipment for their production

- Organisations in the field

- $\quad$ Road staff

The following subsystems are necessary for a working asset management:

- Information Management Subsystem collects, systematizes, appraises and archives the basic data of modelling. It utilizes the knowledge on data need, data bases and their operation, archiving, hardware and software need, etc.

- Assets Valuation Subsystem deals with a highly important group of basic data needed for the effective operation of the model. It includes also the methodology of the collection and evaluation of technical data, as well as, the maintenance of the system. 
- Condition Evaluation and Performance Modelling Subsystem concentrates on the actual condition of system elements and the modelling of their expected performance. The subsystem includes the condition parameters of each element, the scaling of the measurement range of condition parameters, as well as, the data storage in close connection with the activity of other subsystems.

- Deterioration Modelling and Defect Analysis Subsystem forecasts the worsening of the condition of various system elements, identifies the probable (expected) defect types. The condition of an element can be characterized by various qualifying parameters or a combined index; the deterioration curves are set accordingly.

- Maintenance, Operation, Rehabilitation and Reconstruction Subsystem defines the types and the costs of various intervention techniques. It is a very important supporting element for the establishment of the decision strategies.

- Whole Life Cost and Benefit Subsystem also has a significant supporting role for the decision process. Here, among others, the discounted values, the inflation rate, the interest rates are taken into consideration.

- Decision Supporting Models Subsystem determines the use and the applicability of the whole system. Since there are a high number of elements in a system, a complex model creating total optimum for strategic decisions should be extremely aggregated. So, expert models, methods using basis approach, optimization models can be applied here. The already existing system elements (PMS, BMS, systematic condition survey, etc.) should be also included into the system.

- Total Quality Management Subsystem is operational during the whole implementation period of the program. It provides the results and the performance efficiency of the intervention at the end of the period. After feedback, new strategic and tactical objectives are set. When their parameters are set, the whole decision process can be restarted.

Over 20 years ago the systematic management modelling of transport infrastructure started in Hungary with the collaboration of experts in various fields (transport engineers, mathematicians, economists, meteorologists, etc.). The original goal was to develop cost-efficient systems for development, rehabilitation, maintenance and operation activities in the area. These models can provide effective tools for infrastructure (mainly road) managers to minimize their expenditures if given preconditions are fulfilled.

This paper presents the development phases of such a model that concentrates not only on economic aspects but also environmental (sustainability) ones, as well. (Again, the importance of the problem can be highlighted by the fact that the net value of Hungarian public highway network - some 7,000 billion HUF $=28$ billion EUR - exceeds $38 \%$ of the Hungarian national wealth). The main steps of this 
development process are: single stage network level optimization model, multistage model, combined pavement/bridge model, model with climate-dependent parameters, model with traffic-dependent parameters, towards asset management.

\section{Single Stage Network Level Optimization Model}

The development of the first Hungarian network level pavement management system was preceded by the creation of an effective, large-scale road data bank (Bakó et al. [4]). It was decided to deal with network level pavement management models before project level ones since the former variants need less previous information on the roads concerned (Bakó et al. [11]). The main aim of a network level management model is to identify the most advantageous maintenance techniques for every road subset with the same surface type, same condition parameters and same traffic category. This type if model is a budget planning tool capable of estimating the total lengths and costs of works required on the network for pavement rehabilitation, resurfacing and routine maintenance. A financial planning type is generally connected with the determination of the funding level needed to maintain the "health" (integrity) of the pavement network at a desirable level. In case of another model type, the available budget is known and the maintenance strategy has to be determined that fulfil the required constraint of pavement conditions, and optimize the total benefit of society (Gáspár et al. [18, 22]).

The first single-stage network level optimization model (MPMS) was developed in Hungary in the late 1980s (Bakó [5], Gáspár [17]). The Hungarian road administration needed quick and practical results which could not be provided by the "too simple" MPMS. That is why the Finnish HIPS model (Männistö [27]) was chosen, because there were already available several-year experiences. The new version, the so-called HUPMS-model was developed using the optimization procedure of MPMS and the model structure of HIPS.

The main features of this model are:

- Several (a maximum of 10) time periods (stages)

- 2 pavement types (asphalt concrete and asphalt macadam)

- 3 traffic categories

- 4 condition parameters (unevenness, bearing capacity, rut depth, surface defects)

- Combined target function

- Max. 8 intervention (rehabilitation) types

In the long-term model, the optimum solution is sought for the distribution of pavement condition in the road network which can be attained after the optimum 
interventions; it is called the Markov-stable condition. The target function is the minimum of the sum of agency and user costs (i.e. social total optimum).

Possible interventions (rehabilitation strategies) for asphalt concrete roads are: routine maintenance, patching, rut repair, surface dressing, laying thin asphalt course, asphalt overlay, and reconstruction. The interventions for asphalt macadam roads are: routine maintenance, patching, surface dressing, road profile repair, asphalt overlay, reconstruction.

The Markov transition probability matrix for pavement type $\mathrm{i}$, traffic category $\mathrm{j}$, and intervention type $\mathrm{k}$ is designated by $\mathrm{Q}_{\mathrm{ijk}}$. The matrix size amounts to $135 \times 135$, since the total possible number of relevant parameters is $3 \times 3 \times 3 \times 5=135$. The number of Markov matrices is $2 \times 3 \times 8=48$; thus the number of columns in the model amount to: $48 \times 135=6480$.

The unknown vector of pavement type $\mathrm{i}$, traffic category $\mathrm{j}$, and intervention type $\mathrm{k}$ should be $\mathrm{X}_{\mathrm{ijk}}$, which shows the proportion of road link lengths in 135 condition states for a given $\mathrm{i}, \mathrm{j}, \mathrm{k}$. The number of vectors is 48 , and so the total number of unknown factors reaches 6480 .

The unit intervention costs vector for pavement type $i$, traffic category $j$, and intervention type $\mathrm{k}$ should be $\mathrm{C}_{\mathrm{ijk}}$. The road user cost function for pavement type $\mathrm{i}$ and traffic category $\mathrm{j}$ is designated by $\mathrm{K}_{\mathrm{ij}}$. First, the Markov-stable model was formulated.

When the notation above are applied, the model is as follows. Determine the unknown vector series $\mathrm{X}_{\mathrm{ijk}}$ is sought, which fulfils the Markov stable condition

$$
\sum_{i=1}^{2} \sum_{j=1}^{3} \sum_{k=1}^{8}\left(Q_{i j k}-E\right) X_{i j k}=0
$$

and minimises the weighted sum of agency (intervention) and user costs:

$$
C=\alpha \sum_{i=1}^{2} \sum_{j=1}^{3} \sum_{k=1}^{8} X_{i j k} C_{i j k}+\beta \sum_{i=1}^{2} \sum_{j=1}^{3} \sum_{k=1}^{8} X_{i j k} K_{i j} \longrightarrow M I N
$$

where $\mathrm{E}$ unit matrix of size $135 \times 135$,

$\alpha$ weighting factor for intervention costs,

$\beta$ weighting factor for user costs.

Further conditions limiting the amount of intervention costs can be supplied for the model. This case, the Markov stable solution is looked for which fulfils all conditions considered. 


\section{Multi-Time Period Model}

The multi time period, (briefly multiperiod) version of the PMS, was created in 1991 (Csicselyné [13]; Gáspár [19]; Bakó [8]). One of the objectives is to reach a stable model result by means of an approximation over a period of several years. The number of time periods is generally 10 , and the model gives the necessary interventions in each period. Let us denote by $\mathrm{Y}_{\mathrm{ijt}}$ the proportion of the length of the road sections of pavement type $i$ and traffic category $j$ after the interventions carried out during the year $t$, while $b_{i j}$ is the proportion of the length of the road sections of pavement type $i$ and traffic category $j$ or, initially, at the beginning of the planning period.

This case, the unknown vector has a further index t. Let us denote the unknown vector by $\mathrm{X}_{\mathrm{ijkt}}$ that belongs to the time period $\mathrm{t}$.

The first mandatory condition is connected with the distribution of pavement condition states during the initial years:

$\sum_{k=1}^{8} E X_{i j k 1}=b_{i j}, i=1,2, \ldots, s j=1,2, \ldots, f$

$\mathrm{k}=1$

where $\mathrm{E}$ unit matrix of size $135 \times 135$.

The following condition supplies the proportion of road link lengths for the end of the first planning year. So, the proportions of length vectors $Y_{i j 1}$ at the end of the first planning year are determined by the following relation:

$$
\begin{aligned}
& \sum_{k=1}^{8} E X_{i j k 1}=b_{i j}, \mathrm{i}=1, .2, \mathrm{j}=1,2,3 \\
& \sum_{k=1}^{8} Q_{i j k} X_{i j k 1}=y_{i j 1}, \mathrm{i}=1, .2, \mathrm{j}=1,2,3
\end{aligned}
$$

The following mandatory conditions refer to the later years:

$$
\sum_{i=1}^{2} E X_{i j k(t+1)}-Y_{i j t}=0, \mathrm{j}=1,2,3, \mathrm{k}=1,2, \ldots 8, \mathrm{t}=1,2, \ldots 9
$$

This condition means that the proportion of length $\mathrm{Y}_{\mathrm{ijt}}$ at the end of time period $t$ provides a value for the initial distribution for the period $(t+1)$ that is it is equal to $\mathrm{X}_{\mathrm{ijk}(\mathrm{t}+1)}$.

A mandatory boundary is the cost limit, where the total intervention costs can be given for a year or for the planning period. The yearly intervention cost limit is as follows: 
$\sum_{i=1}^{2} \sum_{j=1}^{3} \sum_{k=1}^{8} r^{(l-1)} C_{i j k} X_{i j k t} \leq r^{(t-1)} M, \mathrm{t}=1,2, \ldots 10$

where $\quad \mathrm{r}$ the discount factor,

M the intervention cost available annually.

The target pavement condition distribution at the end of the planning period can also be specified:

$$
\begin{aligned}
& \sum_{i=1}^{2} \sum_{j=1}^{3}\left(Y_{i j T}\right)_{v} \geq \delta_{1} \sum_{i=1}^{2} \sum_{j=1}^{3}\left(b_{i j}\right)_{v}, v \in \mathrm{G} \\
& \sum_{i=1}^{2} \sum_{j=1}^{3}\left(Y_{i j T}\right)_{v} \leq \delta_{2} \sum_{i=1}^{2} \sum_{j=1}^{3}\left(b_{i j}\right)_{v}, v \in \mathrm{B} \\
& \left(\underline{b}_{E}\right)_{v} \leq \sum_{i=1}^{2} \sum_{j=1}^{3}\left(Y_{i j T}\right)_{v} \leq(\bar{b} E)_{v}, v \in \mathrm{E}
\end{aligned}
$$

where $\mathrm{T}$ the number of the planning periods,

$\mathrm{G}, \mathrm{B}, \mathrm{E}$ three sets the pairwise intersection of which is 0 , and the sum of these sets is the set of the road segment,

$\mathrm{G}$ the set of the road segments which are in good condition,

B set of the road segments which are in bad conditions,

E the set of the road segments which ere in average conditions,

$\underline{b}_{E} \quad$ the lower bound vector of the other road segment group,

$\bar{b}_{E} \quad$ the upper bound vector of the other road segment group,

$\delta_{1}$ and $\delta_{2}$ constants.

In this case, a combined target function was selected which can be considered as the weighted average of the intervention cost and the user cost target function types:

$$
C=\alpha \sum_{i=1}^{2} \sum_{j=1}^{3} \sum_{k=1}^{8} \sum_{t=1}^{10} X_{i j k t} C_{i j k}+\beta \sum_{i=1}^{2} \sum_{j=1}^{3} \sum_{t=1}^{9} Y_{i j t} K_{i j} \longrightarrow M I N \text { ! }
$$


If $\alpha=0$ only the user costs are considered in the target function, while in the case of $\beta=0$, only the intervention costs are.

In such a way, these cost function types can be arbitrarily weighted by varying both constants.

\section{Combined Pavement/Bridge Management}

In the majority of countries - including Hungary - the PMS (Pavement Management System) and BMS (Bridge Management System) operate independently. However, their interdependence is obvious since the bridge surfacing constitutes part of the road pavement. Very often their financial sources are also identical (e.g. Road Funds) contributing to the need for more or less common management. Both PMS and BMS apply the same concept and application of system technology and require a system output function that can be optimised in relation to the benefits and costs.

Several models can be used for solving the BMS problem. It can be a mathematical programming (linear, dynamic, nonlinear, integer, etc.) model. It could be a stochastic model or a fuzzy approach. In all models, the most important and difficult problem is to develop a proper deterioration model.

In Hungary, both the adapted PONTIS-H Bridge Management System and the HIPS-HUPMS network level Pavement Management System are based on the use of Markov transition probability matrices (Bakó et al., [10]). As a result, their identical structures allow the joint optimisation of both systems. This activity is especially important when the aim is the distribution of the funds available between the two infrastructure elements (road pavements and bridges).

The mathematical-engineering model of this BMS-PMS (PBMS) a common model has already been completed. Its implementation is planned for the near future.

As mentioned above, the deterioration sub-model of the Hungarian network level PMS (HUPMS) utilises Markov transition probability matrices. The bridge management model, the PONTIS, also uses them. However, a combined pavementbridge management model cannot be developed using them because their module structures are different. That is why the mathematical model (PBMS-model) of the network-level pavement-bridge management has been developed which optimizes in a single model.

The structure of this model is presented in Figure 1. It has two columns. The first column (P1 and P2) contains the elements of the PMS model introduced earlier when discussing HUPMS (see conditions set out in Eqs. 3-5, 7). 
In the right-hand column the relevant BMS conditions (Golabi et al [23]; Agárdy et al [1]) can be seen; the yearly cost boundary for the Bridge Management System is as follows:

$$
\begin{array}{cll}
\sum_{d=1}^{D} \sum_{e=1}^{E} \sum_{f=1}^{F} \sum_{g=1}^{G} r^{(t-1)} V_{d e f g} & H_{d e f g} \leq r^{(t-1)} B \quad t=1,2, \ldots T \\
\text { where } & \mathrm{V}_{\text {defgt }} & \text { intervention costs } \\
\mathrm{H}_{\text {defg }} & \text { user costs } \\
\mathrm{r} & \text { discount factor } \\
\mathrm{B} & \text { yearly cost boundary } \\
\mathrm{d} & \text { bridge span } \\
\mathrm{e} & \text { bridge element } \\
\mathrm{f} & \text { level of exposure } \\
\mathrm{g} & \text { intervention type }
\end{array}
$$

The object is to define a vector series which fulfils the conditions defined, and minimises the weighted sum of the intervention and user costs, that is:

$$
\sum_{d=1}^{D} \sum_{e=1}^{E} \sum_{f=1}^{F} \sum_{g=1}^{G} \sum_{t=1}^{T} r^{(t-1)} V_{d e f g} H_{d e f g}+\mu \sum_{d=1}^{D} \sum_{e=1}^{E} \sum_{f=1}^{F} \sum_{t g=1}^{T} r^{(t-1)} W_{d e f t} I_{d e f} \longrightarrow M I N
$$

where the elements of $I_{\text {def }}$ related to user costs are different from 0 .

The PBMS model can also have common conditions, for example relating to the annual sum which is commonly available, that is, the sum of the conditions set out in Eqs. 6 and 9:

$$
\sum_{i j k} r^{(t+1)} C_{i j k t} X_{i j k t}+\sum_{d e f g} r^{(t+1)} V_{\text {defgt }} H_{\text {defgt }} \leq r^{(t-1)}(M+B), \quad t=1,2, \ldots T
$$

As target function, the sum of the object functions of pavement and bridge models is taken. The object can be here the minimisation of the intervention costs $(\mathrm{P} 4+$ $\mathrm{B} 4)$, the minimisation of user costs $(\mathrm{P} 5+\mathrm{B} 5)$ or the weighted sum of these costs when none of the weighting factors is equal to $0(\mathrm{P} 6+\mathrm{B} 6)$. By varying the parameters, any arbitrary combination of the target function can be produced. For example, the minimisation of the sum of road (pavement) user costs and bridge intervention costs.

P1 Markov matrices for road pavements 


\begin{tabular}{|l|l|}
\hline & B1 Markov matrices for bridges \\
\hline $\begin{array}{l}\text { P2 Conditions for road pave- } \\
\text { ments }\end{array}$ & B2 Conditions for bridges \\
\hline & \\
\hline P3+B3 Conditions common to road pavements and bridges \\
\end{tabular}

Target functions

\begin{tabular}{|ll|}
\hline P4+B4 User costs & MIN! \\
\hline
\end{tabular}

\begin{tabular}{|ll}
\hline P5+B5 Intervention costs & MIN! \\
\hline
\end{tabular}

P6+B6 Weighted intervention and user costs MIN!

Figure 1

Combined model of PMS and BMS

\section{Consideration of Climate Change}

Typically, road asset management models usually do not consider environmental load (connected with climate change consequences) (Gáspár et al. [20]).

In case of long-term, multi-time period models, two approaches could be:

A) Environmental effects forecasted for the whole planning period, $M+R$ actions are calculated accordingly,

B) Following forecasting in model A, environmental consequences are calculated after each time period resulting in an input of next time period (more accurate results)

$\sum_{s=1}^{S} \sum_{f=1}^{F} \sum_{p=1}^{P}\left|\overline{\mathbf{X}}_{\mathbf{s f p}} \mathbf{C}_{\mathbf{s f p}}-\mathbf{X}_{\text {sfpt }} \mathbf{C}_{\mathbf{s f p}}\right| \rightarrow \min , \quad t=1, \ldots, T$

As a next step, the target function is linearized. The two artificial variables are denoted by $\mathbf{u}_{i j k t}$ and $\mathbf{v}_{i j k t}$. Besides the following equation has to be met:

$$
\begin{gathered}
\mathbf{u}_{\text {sfpt }}-\mathbf{v}_{\text {sfpt }}=\overline{\mathbf{X}}_{\text {sfp }} \mathbf{C}_{\text {sfp }}-\mathbf{X}_{\text {sfpt }} \mathbf{C}_{\text {sfp }}, \quad \text { ahol } \mathbf{u}_{\text {sfpt }} \geq \mathbf{0} \text { és } \mathbf{v}_{\text {sfpt }} \geq \mathbf{0}, \\
s=1, \ldots, S, \quad f=1, \ldots, F, \quad p=1, \ldots, P, \quad t=1, \ldots, T .
\end{gathered}
$$


and the new objective function in this case is

$$
\sum_{s=1}^{S} \sum_{f=1}^{F} \sum_{p=1}^{P}\left(\mathbf{u}_{\mathrm{sfpt}}+\mathbf{v}_{\mathrm{sfpt}}\right) \rightarrow \min , \quad t=1, \ldots, T
$$

Just one of the coordinates $\mathbf{u}_{\text {sfpt }}$ and $\mathbf{v}_{\text {sfpt }}$, can be different to 0 any time. The remaining steps are identical to the ones mentioned before. The conditions (constraints) in Eq. 13 change in every planning time period $t$.

Besides, two new Bridge Management models were also developed. The above mentioned PONTIS and its Hungarian version seemed to be rather far from the real processes. The new models could handle the deterioration process of bridge elements more realistically.

\section{Some Related Models}

Some other related management models were also developed that are presented briefly.

\subsection{Model for Funds Distribution}

One of the outputs of the network level HUPMS is the "optimal" distribution of available highway funds for country-wide links of Hungarian public road network. The next necessary step is the continuation of funds distribution (allocation), among others, to the road network of various counties and the motorway network. To solve this problem, a computerized model was developed (Bakó [6]; Bakó [7]) with the following features.

First, the so-called expenditure groups (e.g. patching, grass mowing, bridge management, overhead of road management organisations, etc.) were identified. The task is to distribute "optimally" the available highway funds among these expenditure groups. The expenditure groups are denoted by "i", their number is "l". The running index of road management units (e.g. County Highway Directorate) should be " $\mathrm{j}$ ", while their number amounts to "J". The task is to determine an unknown $X=\left(x_{i j}\right)$ matrix an element of which is $x_{i j}$, the sum coming from the funds " $i$ " and destined to the road management unit " $j$ ". Denote the sum available for the expenditure group "i" by " $b_{i}$ ". This sum can be determined either by the actual needs or by the so-called basis allocation in the previous year or, eventually, using another methodology.

The sums to be allocated to a road management unit is influenced by its special quantitative parameters, like total length of the road network managed, traffic amount, number of traffic signs, etc. These qualitative parameters are usually 
proportional with the works to be done and the related sum of money. The first qualitative parameter of the expenditure group "i" and road management unit " $\mathrm{j}$ " is designated by $z_{i j}^{(l)}$, the second one by $\mathrm{z}_{\mathrm{ij}}^{(2)}$ and the $\mathrm{k}^{\text {th }}$ one by $\mathrm{z}_{\mathrm{ij}}^{(\mathrm{k})}$. For the sake of simplicity, a special methodology was used for the calculation of a characteristic rate of the road management unit in order to apply a single qualitative parameter for a unit.

In addition to the qualitative parameters, unit costs were also given for each expenditure group and road management unit. These unit costs can be the same for each road management unit (e.g. road pavement condition evaluation), but they can be different for various management units as a function of their location, natural features, etc. The unit cost of the expenditure group " $\mathrm{i}$ " and road management unit " $\mathrm{j}$ " should be denoted by $e_{i j}$. It is supposed that the benefit of the activity in question for the expenditure group " $i$ " and road management unit " $\mathrm{j}$ " amounts to $h_{i j}$ for 1 HUF expenditure. The task is to perform the optimal distribution of the funds available. There are several solution methodologies (optimization procedures resulting linear programming tasks, heuristic methods, simulation, expert system, etc.) depending on the targets set, the amount of inputs available and some other parameters.

The linear programming model distributes (allocates) optimally the funds available to the expenditure groups when also the benefits are known. One of the conditions for the use of the model is that, in case of a fixed expenditure group, the total funds allocated by this title for the road management units should reach $b_{i}$ that is destined for the expenditure group:

$$
\sum_{j=\underline{1}}^{J} x_{i j} \geq b_{i}, \quad \mathrm{i}=1,2, \ldots, \mathrm{I}
$$

Another constraint is the individual lower limit for each variable

$$
x_{i j} \geq \frac{b_{i} \cdot z_{i j}}{\sum_{k=1}^{J} x_{i k}} j=1,2, \ldots, I
$$

The target function should be the maximization of the benefit coming from the maintenance-rehabilitation action. Since neither $x_{i j}$, nor $k_{i j}$ are positive values, the task would be unlimited. That is why an additional limiting condition is defined for which the sum $\mathrm{K}$ is needed, the total financial means available for highway purposes. It is supposed that the following relationship between the limit given for an expenditure group and the sum $\mathrm{K}$ is valid:

$$
\sum_{i=1}^{I} b_{i} \leq K
$$


If this relationship is not valid, another model will be used for solving the task. This case, the target value is the maximization of benefit:

$\sum_{i=1}^{I} \sum_{j=1}^{J} h_{i j} x_{i j} \rightarrow \operatorname{Max}$

As a summary, the model can be defined as follows: let us determine the unknown matrix $\mathrm{X}=\left(x_{i j}\right)$, which fulfils the following constraints:

$$
\begin{aligned}
& \sum_{j=1} x_{i j} \geq b_{i}, \quad \mathrm{i}=1,2, \ldots, \mathrm{I} \\
& \sum_{i=1}^{I} \sum_{j=1}^{J} x_{i j} \leq K \\
& x_{i j} \geq \frac{b_{i} z_{i j}}{\sum_{k=1}^{J} x_{i k}} \quad i=1,2, \ldots, I \\
& j=1,2, \ldots, J
\end{aligned}
$$

and the value of target function would be maximal:

$$
\sum_{i=1}^{I} \sum_{j=1}^{J} x_{i j} \cdot h_{i j} \rightarrow M A X !
$$

The above task is a linear programming model that consists of linear conditions and a target value. Some of the expenditure groups are not included in the optimization since they are of fixed costs, as, for example, the operation expenditures of the road management unit. This kind of cost item is known, so, it can be simply deducted from the whole sum destined to road management. Of course, a model can be developed also for the determination of the operation costs of these organizations, and the nearly objective allocation of these sums.

\subsection{Model for the Allocation of the Operation Costs of Road Management Units}

Denote the operation costs needed (or actually used in the previous year) for the first unit by $L_{1}$, for the second one by $L_{2}, \ldots$ and for the $\mathrm{j}^{\text {th }}$ organization by $L_{j}$. (Bakó [7]). Supposing that these needed or previously actually used sums of money are not inaccurate, the following total sum has to be spent for the operation of road management units:

$$
L=\sum_{j=1}^{J} L_{j}
$$


The allocation (distribution) of this total sum among road operators can be determined more or less objectively. The task can be solved by using the quantitative parameters mentioned before; some of these parameters can be:

a) The total length of the road network managed by the organisation

b) The sum of the road sections managed weighted by their traffic volumes

c) Weighted operation tasks of the unit considering several qualitative parameters as total road length, traffic size, number, types and surfaces of bridges, number of traffic signs, etc.

d) Sizes proportional to other operational tasks to be done

The cases a.) and b.) will be presented briefly

For the case a.), the funds needed for a road management unit can be allocated based on the total road length managed by the unit in question. Denote the total road lengths managed by the $1^{\text {st }}, 2^{\text {nd }}, \ldots . \mathrm{j}^{\text {th }}$ road management units by $m_{1}, m_{2}, \ldots . . m_{j}$. Then the operational costs of the organization projected to $1 \mathrm{~km}$ road length are as follows: $f k=\frac{\sum_{j=1}^{J} L_{j}}{\sum_{j=1}^{J} m_{j}}=\frac{L}{M}$

The operational costs of the $\mathrm{j}^{\text {th }}$ road management unit can be determined using $\mathrm{m}_{\mathrm{j}}$ :

$f k_{j}=m_{j} * f k$

where $f k_{j}$ denotes the sum destined to $\mathrm{j}^{\text {th }}$ road management unit in the expenditure group in question (that is $x_{l j}$, where i denotes the row related to the operation of the organisation in the matrix $\mathrm{X})$.

In the allocation variant b.), also the traffic volume $A_{s}$ is known for each road section $u_{s}$. The traffic volume can be characterized by AADT, ESAL or a modified ESAL (Gáspár [16]). Then the road section lengths weighted by their traffic volumes have to be calculated for any $\mathrm{j}^{\text {th }}$ road management unit.

$m_{j}^{\prime}=\sum_{s=1}^{p} u_{s} A_{s}$

where $p$ is the number of homogeneous road sections managed by the $j^{\text {th }}$ road management unit

After having calculated the weighted $m_{j}^{\prime}$ values, the sum of money for a weighted $1 \mathrm{~km}$ long section is to be determined using the following equation: 


$$
f k^{\prime}=\frac{\sum_{j=1}^{J} L_{j}}{\sum_{j=1}^{J} m_{j}^{\prime}}
$$

Then the funds needed by road management units can be calculated without any problem. The value $f k^{\prime}$ for $1 \mathrm{~km}$ road section weighted by traffic size and the values $m_{j}^{\prime}(\mathrm{j}=1,2, \ldots \mathrm{J})$ are used in the determination of funds need:

$$
f k_{j}^{\prime}=m_{j}^{\prime} * f k^{\prime}
$$

The values $f k_{j}(\mathrm{j}=1,2, \ldots, \mathrm{J})$ can be fine tuned if other tasks of the road management unit are included in the weighting process.

\subsection{Simultaneous Consideration of Several Quantitative Parameters}

It is supposed that $\mathrm{P}$ various quantitative parameters are related to the $\mathrm{i}^{\text {th }}$ road management unit. It means that this expenditure group is connected with tasks on various quantitative parameters. For the sake of simplicity, the index $\mathrm{i}$ will be omitted, that is $z_{j}^{(k)}$ is used instead of $z_{i j}^{(k)}(\mathrm{j}=1,2, \ldots . \mathrm{J}, \mathrm{k}=1,2, \ldots \ldots . \mathrm{P})$. Accordingly, $x_{j}$ is applied instead of $x_{i j}$, that is the index $\mathrm{i}$ is omitted. The sums related to quantitative parameters are nationally fixed. These values are given from the actual use of previous year or come from expert or professional political decisions.

The task is the determination of the sum of $x_{j}$ (allocated to $\mathrm{j}^{\text {th }}$ road management unit in this expenditure group) based on the known $z_{j}^{(k)}$ quantitative parameters and the $W^{(k)}$ row sums related to the given qualitative parameters.

Since there are several qualitative parameters in the expenditure group in question, the $x_{j}$ can be calculated as the sum of $x_{j}^{(k)}$ elements related to the qualitative parameters $\mathrm{k}=1,2$....P. The elements $x_{j}^{(k)}$ are calculated in the ratio of the connected qualitative parameters.

The quantities $x_{j}$ and $x_{j}^{(k)}$ have to satisfy the following relationships:

$$
\sum_{j=1}^{J} x_{j}=w
$$




$$
\begin{array}{ll}
\sum_{j=1}^{J} x_{j}^{(k)}=w^{(k)}, & \mathrm{k}=1,2, \ldots, \mathrm{P} \\
\sum_{k=1}^{K} w^{(k)}=w & \\
\sum_{k=1}^{K} x_{j}^{(k)}=x_{j}, & \mathrm{j}=1,2, \ldots, \mathrm{J}
\end{array}
$$

where the values $\mathrm{w}$ and $w^{(k)}$ are known.. The values $x_{j}^{(k)}$ are calculated, in the ratio of $\mathrm{k}^{\text {th }}$ qualitative parameter, as follows:

$x_{j}^{(k)}=\frac{w^{(k)} z_{j}^{(k)}}{\sum_{l=1}^{J} z_{l}^{(k)}} \quad \mathrm{k}=1,2, \ldots, \mathrm{P}$

The $x_{j}$ sum of money related to $\mathrm{j}^{\text {th }}$ road management unit can be even directly calculated using the above equations, as follows:

$$
x_{j}=\sum_{k=1}^{K} \frac{w^{(k)} z_{j}^{(k)}}{\sum_{k=1}^{J} z_{l}^{(k)}} \quad \mathrm{j}=1,2, \ldots, \mathrm{J}
$$

Another option for the calculation of the funds allocated to the road management unit, to consider the ratio between the actual expenditures in the previous year. The only difference from the procedure presented before is the use of following equation:

$x_{j}=\frac{W \cdot L_{j}}{\sum_{l=1}^{J} L_{l}} \quad \mathrm{j}=1,2, \ldots, \mathrm{J}$

It should be noted that the above algorithm can be fine-tuned by the inclusion of additional parameters.

\subsection{Treating with Insufficient Funds}

It is a usual situation that the sum of needed funds exceeds the available ones, consequently: 
$\sum_{i=1}^{I} b_{i}>K$

where $\mathrm{K}$ equals to the whole funds available. This case, another optimization model could be used that will be briefly shown.

Since the sum of elements bi (actually the total demand) is above the financial resources available, the following constraint is set for the sum of the funds to be allocated:

$\sum_{i=1}^{I} \sum_{j=1}^{J} x_{i j}=K$

The sum of the funds to be distributed to each expenditure group cannot exceed the total need in the same expenditure group:

$\sum_{j=1}^{J} x_{i j} \leq b_{i} \quad \mathrm{i}=1,2, \ldots, \mathrm{I}$

The equality of the sums of rows is also required in the model:

$\sum_{j=1}^{J} x_{i j}=\gamma_{j} b_{j}$

This case, the target function is the minimization of the needed and the allocated sums of rows:

$\prod_{j=1}^{J} \gamma_{j} \rightarrow$ MIN

This target function is nonlinear, that is why the task can be formulated in a nonlinear model. Following this principle, a more general model was formulated.

In this model, it is supposed that the real value of the funds available in the previous years exceeded the funds that are presently available. Denote the funds used in previous (e.g. preceding) years the matrix $\mathrm{F}$ the element $f_{i j}$ of which is the financial means used by the $\mathrm{j}^{\text {th }}$ road management unit in the $\mathrm{i}^{\text {th }}$ expenditure group. The sum of the row I of Matrix $\mathrm{F}$, that is the funds used in $\mathrm{i}^{\text {th }}$ expenditure group would be denoted by $f_{i}$. The symbol of $f^{(j)}$ means the column sum $\mathrm{j}$, that is the total funds used by the $\mathrm{j}^{\text {th }}$ road management unit. Furthermore the available funds $\mathrm{K}$ are also known. It is supposed to be less than the funds used in the previous years or needed in the present year.

The task is the calculation of the matrix $\mathrm{X}=\left(x_{i j}\right)$, actually the funds for $\mathrm{i}^{\text {th }}$ expenditure group and $\mathrm{j}^{\text {th }}$ road management unit. The sum of all elements of matrix $\mathrm{X}$ has to be equal to the value of funds $\mathrm{K}$ : 
$\sum_{i=1}^{I} \sum_{j=1}^{J} x_{i j}=K$

If the sum of $b_{j} \mathrm{j}=1.2, \ldots, \mathrm{J}$ is known, the following relationship has to be fulfilled:

$\sum_{i=1}^{I} x_{i j} \geq b_{j}, \quad \mathrm{j}=1,2, \ldots, \mathrm{J}$

The target is to determine a matrix that is similar to the other one as much as possible. For the measure of similarity, any of the known parameters can be applied, e.g. the Kulback measure (Klafszky, [26]). In the case of the vectors $a=$ $\left(a_{1}, a_{2}, \ldots a_{n}\right)>0$ and $\mathrm{b}=\left(b_{1}, b_{2}, \ldots, b_{n}\right)>0$ is given by the following equation:

$\sum_{i=1}^{n}\left(a_{i} \log \frac{a_{i}}{b_{i}}-a_{i}+b_{i}\right)$

Using the Kulback measure, the similarity can be determined, in the case of matrices $\mathrm{F}$ and $\mathrm{X}$, in the following cases:

a) Similarity of the sums (that is sums of rows) allocated to expenditure groups

b) Similarity between the funds allocated to the road management units in the preceding year and this year

c) Similarity between the sums distributed in the preceding and the present year, actually the similarity of the matrices $\mathrm{X}$ and $\mathrm{F}$

So, the target function is the minimization of the measures a.)-c.). In the case of expenditure group comparison - version a.) -, the target function is:

$$
g_{1}\left(f_{j}, x_{i j}\right)=\sum_{j=1}^{J}\left(f_{j} \log \frac{f_{j}}{\sum_{i=1}^{I} x_{i j}}-f_{j}+\sum_{i=1}^{I} x_{i j}\right) \rightarrow M I N
$$

In the case of similarity between the funds allocated to the road management units, - version b.) -following relationship has to be minimized:

$$
g_{2}\left(f^{(j)}, x_{i j}\right)=\sum_{i=1}^{I}\left(f^{(i)} \log \frac{f^{(i)}}{\sum_{j=1}^{J} x_{i j}}-f^{(i)}+\sum_{j=1}^{J} x_{i j}\right) \rightarrow M I N
$$


In the case of the similarity between the sums distributed in various years, - variant c.) - following target function has to be applied:

$$
g_{3}\left(f_{i j}, x_{i j}\right)=\sum_{i=1}^{I} \sum_{j=1}^{J}\left(f_{i j} \log \frac{f_{i j}}{x_{i j}}-f_{i j}+x_{i j}\right) \rightarrow M I N
$$

If all the three cases are considered, the target function is the weighted minimization of the cases a.)-c.):

$$
\alpha_{1} g_{1}\left(f_{j}, x_{i j}\right)+\alpha_{2} g_{2}\left(f^{(i)}, x_{i j}\right)+\alpha_{3} g_{3}\left(f_{i j}, x_{i j}\right) \rightarrow M I N
$$

The above target function includes the preceding ones, as well, because in case of $\alpha_{2}=\alpha_{3}=0$, the target function of variant a.), in the case of $\alpha_{1}=\alpha_{3}=0$, the target function of variant b.), while in the case of $\alpha_{1}=\alpha_{2}=0$, the target function of variant c.) are given. The determination of the parameters $\alpha_{i}$ can be the result of a professional-political decision, since the primary goal and the stimulus have to be always considered.

Summarizing the model, the following nonlinear task has to be solved. Determine the matrix $\mathrm{X}=\left(x_{i j}\right)$ for which the following conditions are met:

$$
\begin{aligned}
& \sum_{i=1}^{I} \sum_{j=1}^{J} x_{i j}=K \\
& \sum_{j=1}^{J} x_{i j} \geq b_{i} \quad \mathrm{i}=1,2, \ldots, \mathrm{I}
\end{aligned}
$$

and the following target function is minimal:

$$
\alpha_{i} \sum g_{1}\left(f_{j}, x_{i j}\right)+\alpha_{2} g_{2}\left(f^{(i)}, x_{i j}\right)+\alpha_{3}\left(f_{i j}, x_{i j}\right) \rightarrow M I N
$$

\section{Conclusions}

As mentioned earlier, several subsystems exist already in Hungary, in the field of Transport Asset Management. The systematic trial section monitoring has begun more than a decade ago. Asset value calculations, related to bridges and roads, is also performed regularly. We have urban, motorway and highway PMS systems, as well.

A combined PMS-BMS model has been also completed. The generalization of this model system is under development.

The first version of the model family consists of the following parts:

- The exact mathematical model (e.g. BMS + PMS) 
- Normative model for some other elements

- Cost/benefit type models

The network-level multi-stage HUPMS model was developed further by applying climate-dependent and traffic-dependent parameters.

Furthermore, some other related management models (model for funds distribution; allocation of the operation costs of road management units; simultaneous consideration of several quantitative parameters; treating with insufficient funds) developed were also presented briefly.

Future plans are to develop further the above models for their inclusion into an effective Road Asset Management System.

\section{References}

[1] Agárdy, Gy., Bakó, A., Gáspár, L., Kolozsi, Gy., Lublóy, L., Molnár, I.: Adaptation of PONTIS BMS to Hungarian conditions. Proceedings of $4^{\text {th }}$ Bridge Engineering Conference, AUSTROADS, Adelaide (South Australia) 2000, pp. 61-70

[2] Asset Management for the Road Sector, 2001, OECD, 83 p.

[3] Asset Management Premier, US Department of Transportation, FHWA, Office of Asset Management, 1999, 30 p.

[4] Bakó, A., Gyulai L., Erben, P: Structure of the Road Data Bank, Proceedings of the Pavement Management System, Budapest, 1989, pp. 43-47

[5] Bakó, A.: Mathematical Model for the first Hungarian network level PMS, Közlekedésépítési és Mélyépítéstudományi Szemle No. 2, 1991, pp. 68-72 (In Hungarian)

[6] Bakó A.: Programming system for funds distribution and its handling, Algorithm and Program Handling Guide. Ministry for Transport, Telecommunication and Water Management, Budapest (In Hungarian), 1992

[7] Bakó A.: Solving funds need and distribution using computer, Transport and Civil Engineering Scientific Review No. 1, 1994, pp. 39-44 (In Hungarian)

[8] Bakó, A.: Linear Multistage Optimization System, Periodica Politechnica No. 4, 1996, pp. 53-63

[9] Bakó A.: Combined network level road pavement-bridge management system, Közúti Közlekedés és Mélyépitéstudományi Szemle No. 3, 1997, pp. 96-100 (In Hungarian)

[10] Bakó A., Csicsely-Tarpay M., Gáspár L., Szakos P. The Development and Appli-cation of a Combined Highway Pavement Management System in Hungary, Proceedings of the $4^{\text {th }}$ International Conference on Managing Pavements. Durban (South Africa), Volume 3, 1998, pp. 1091-1105 
[11] Bakó, A., Gáspár, L.: PMS models in Hungary, CD Publishing, Proceedings of $1^{\text {st }}$ European Pavement Management Systems Conference, Budapest, 2000, 8 p.

[12] Bakó, A., Földesi, P., Gáspár, L.: Using Traffic Forecasting Models in Asset Management, CD-ROM Proceedings of the $8^{\text {th }}$ International Conference on Managing Pavement Assets, Santiago, Chile, 2011, 11 p.

[13] Csicselyné, T. M.: Funds Distribution is the Primary Task of the Road Management, Közlekedésépítés és Mélyépítéstudományi Szemle No. 9, 1993, pp. 291-295 (In Hungarian)

[14] Fábián, C. I., Prékopa, A., Ruf-Fiedler, O.."On a Dual Method for a Specially Structured Linear Programming Problem”, Optimization Methods and Software 17, 2002, pp. 445-492

[15] Feighan, K. J., Shanin, M. Y., Sinha, K. C.: A Dynamic Programming Approach to Opti-mization for Pavement Management Systems, Proceedings of $2^{\text {nd }}$ North American Pavement Management Conference, 1988, pp. 2.2195-2.2206

[16] Gáspár L.: Economic asphalt pavement preservation, DSc (Doctor of Sciences Thesis), Hungarian National Academy of Sciences, Budapest, 1988, $263 \mathrm{p}$.

[17] Gáspár, L.: Development of the first Hungarian Network Level PMS, Közlekedéstudományi Szemle No. 4, 1991, pp. 132-141 (In Hungarian)

[18] Gáspár, L., Bakó, A.: Le systéme hongrois de gestion de l'entretien. Revue Générale des Routes et des Aérodromes No. 710, 1993, pp. 34-36

[19] Transportation Research Record 1455. Pavement Management Systems National Academy Press. Washington, D.C., pp. 22-30

[20] Gáspár, L., Bakó, A.: Further Development of Hungarian Road Asset Management due to Climate Change. CD-ROM Proceedings of $4^{\text {th }}$ European Pavement and Asset Manage-ment Conference (Session 5), Malmö, 2012, Sweden, $10 \mathrm{p}$.

[21] Gáspár, L., Karoliny, M.: Investigation and design of durable pavement structure rehabilitation. LAP Lambert Academic Publishing, Saarbrücken, 2015, 101 p.

[22] Gáspár, L.: Actual efficiency of road pavement rehabilitation. CETRA2016 Proceedings of the $4^{\text {th }}$ International Conference on Road and Rail Infrastructure, Sibenik, Croatia, 2016, pp. 181-186

[23] Golabi, K., Thompson, P. D., Hyman, W. A.: PONTIS Version 2.0 Technical Manual. A Network Optimization System for Bridge Improvements and Maintenance, FHWA-SA-94-031, 1993 
[24] Hudson, W. R., Hudson, S. W.: Pavement Management System Proceedings of the $3^{\text {th }}$ International Conference on Managing Pavement, San Antonio (USA), 1994 , pp. 99-111

[25] Hudson W.R., Haas R., Uddin W.: Infrastructure Management, McGrawHill, New York, 1997, 393 p.

[26] Klafszky E.: On the forecast of Input-Output tables, Bulletin of the Hungarian Academy of Sciences SZTAKI, Budapest, Vol. 10, 1973, pp. 1-13 (In Hungarian)

[27] Männistö V.: Network Level PMS Research Report, Budapest, 1995, 35 p.

[28] What is Asset Management Federal Highway Administration, Office of Asset Management, Washington, D.C., 2001 